Bulletin d'Histoire Contemporaine de l'Espagne

$51 \mid 2017$

Les forces politiques durant la Seconde République espagnole

\title{
El republicanismo conservador en los años treinta
}

The conservative republicanism in the thirties

Le républicanisme conservateur dans les années trente

Luis E. Î́ñigo Fernández

(2) OpenEdition

Journals

Edición electrónica

URL: http://journals.openedition.org/bhce/655

DOI: 10.4000/bhce.655

ISSN: 1968-3723

Editor

Presses Universitaires de Provence

Edición impresa

Fecha de publicación: 1 junio 2017

Paginación: 41-52

ISSN: 0987-4135

Referencia electrónica

Luis E. Íñigo Fernández, «El republicanismo conservador en los años treinta », Bulletin d'Histoire

Contemporaine de l'Espagne [En línea], 51 | 2017, Publicado el 09 octubre 2018, consultado el 19 abril 2019. URL : http://journals.openedition.org/bhce/655; DOI : 10.4000/bhce.655 


\title{
El republicanismo conservador en los años treinta
}

\author{
Luis E. Í̃IIGO FERNÁNDEZ
}

Consejería de Educación de la Comunidad de Madrid

$\mathrm{P}$ arece adecuado dar comienzo a esta breve colaboración precisando a qué nos referimos exactamente con el título que la encabeza, pues no faltará incluso quien encuentre en él una verdadera contradictio in terminis, un caprichoso oxímoron de difícil asimilación. Porque, se preguntarán, ¿acaso existió, durante el período que nos ocupa, un republicanismo que no fuera progresista? ¿No eran, quizá, sinónimos evidentes izquierda y República en la España de los años treinta del siglo pasado?

En realidad, semejante identificación sólo podría tenerse por cierta si se refiere a la mayoría del republicanismo español, pero no a su totalidad. Porque, de hecho, sí existió algo que podemos denominar republicanismo conservador, republicanismo de centro o, más sencillamente, republicanismo moderado, aunque se trataba de una corriente del todo minoritaria. La integraban, como hemos precisado en algún otro lugar ${ }^{1}$, varios partidos, dos en los primeros años de la República, tres a partir de 1932, bastante similares desde cualquiera de los parámetros que delimitan el estudio de las fuerzas políticas, como la ideología, el programa, la organización o las bases sociales. Provenían tales fuerzas de orígenes bien diversos. Unos no eran sino republicanos históricos que, años atrás, se habían tornado monárquicos con condiciones y regresaban ahora, en 1931, a las dilatadas falanges del republicanismo; otros, monárquicos que, hastiados de una Monarquía errada en sus planteamientos y cada vez más alejada de la opinión pública, terminaron por mudarse en republicanos. Pero todos ellos recibían sus auténticas señas de identidad de un proyecto político orientado hacia la implantación de una República liberaly democrática, sin mareas ideológicas, aunque abierta, eso sí, a reformas moderadas, lentas y progresivas en el campo de lo social y lo cultural, y capaz de integrar en su seno a la gran mayoría de la opinión pública. Y todos ellos, como es fácil suponer, sellaron su ejecutoria política en el seno del régimen con un rotundo fracaso que condujo a su práctica desaparición como opción política en los meses previos al golpe de estado fallido que dio comienzo a la Guerra Civil.

Explicar por qué se produjo el fracaso de esta opción política y relacionarlo, en la medida de lo posible, con las características propias de los partidos que la secundaban y con el contexto mismo en el que se vieron obligados a impulsarla será el objetivo de las líneas que siguen.

1 Luis ÍNigo FERNÁNDEZ, «E1 republicanismo conservador en la España de los años treinta», Revista de Estudios Politicos, $\mathrm{n}^{\circ} 110$, octubre-diciembre de 2000 , p. 281. Véase también Luis Í̃̃IGo Fernández, La derecha liberal en la Segunda República española, Madrid, UNED, 2000. 


\section{Una ejecutoria errática}

La primera fuerza política llamada a integrar la corriente que nos ocupa fue el Partido Republicano Liberal Demócrata, flamante denominación adoptada el 24 de mayo de 1931 por el antiguo Partido Reformista, fundado en 1912 por Melquíades Álvarez y Gumersindo de Azcárate, al objeto de recalcar su retorno al campo republicano tras haber desertado de él para asumir postulados accidentalistas que le permitieran, llegado el caso, gobernar sin reparos con la Monarquía ${ }^{2}$. La proclamación de la Segunda República, a mediados de abril, había colocado a Álvarez -Azcárate había muerto en 1917- en una posición incómoda, y el aluvión de republicanos de ayer mismo, que recibían las fuerzas impulsoras del nuevo régimen, hacía aconsejable situarse de modo inequívoco entre ellas, borrando de un plumazo pasadas ambigüedades.

Pero la reacción del viejo tribuno asturiano había sido tardía y poco categórica, al menos no lo suficiente para que el resto de los republicanos lo recibieran con los brazos abiertos. Lejos de ello, los seguidores de Melquíades Álvarez fueron rechazados. No se les ofrecieron, sino en muy escasa medida, altos cargos en la nueva Administración republicana, y cuando la modificación de la ley electoral de cara a las elecciones a Cortes Constituyentes dejó claro que sólo los grandes partidos y las coaliciones podían alcanzar una representación importante, republicanos de izquierda y socialistas se negaron a aceptar a los liberales demócratas en sus candidaturas. A ello vino a sumarse el propio retraimiento del PLD en su feudo asturiano, único lugar donde era segura una buena cosecha de escaños, visceral reacción ante lo que Álvarez creyó tolerancia culpable de las autoridades frente a la violencia ejercida contra su partido por las izquierdas. Ambos factores, rechazo ajeno y exclusión propia, condenaron al melquiadismo al status parlamentario de fuerza marginal. Sólo dos diputados obtuvo el PRLD en las Cortes de 1931.

Porque, aunque habían sido pioneros en adoptar posturas templadas en el seno del republicanismo hispano, los melquiadistas no lo habían sido a la hora de capitalizar dicha ventaja ante la opinión pública. Fue, por el contrario, la denominada, tras no pocas dudas, Derecha Liberal Republicana el partido que parecía llamado a convertirse en paradigma del republicanismo conservador en los años treinta. Fruto de la decisión individual de dos políticos monárquicos, Niceto Alcalá Zamora, jefe de una de las facciones del fenecido liberalismo dinástico y dos veces ministro antes de 1923, y Miguel Maura Gamazo, hijo del caudillo conservador Antonio Maura y diputado en las últimas Cortes de la Monarquía, el partido se había constituido en julio de 1930 con el objetivo principal de agrupar dentro de la República, que se tenía ya por inminente, a las fuerzas conservadoras españolas ${ }^{3}$. A pesar del historial nítidamente monárquico de sus fundadores, durante los primeros meses de su existencia pareció a punto de conseguirlo. No sólo estuvieron presentes Miguel Maura y Alcalá-Zamora en la formalización del Pacto de San Sebastián, el 17 de agosto de 1930, sino que éste último fue promovido a la presidencia del comité revolucionario, luego Gobierno provisional, allí constituido, y su formación, una recién llegada a las filas del republicanismo entre las cuales Álvarez era casi el decano, empezó a recibir adhesiones

2 Luis Ínigo Fernández, Melquiades Álvarez. Un liberal en la Segunda República, Oviedo, Real instituto de Estudios Asturianos, 2000. Para la ejecutoria anterior del partido, la mejor síntesis es Manuel SuÁrEz CoRTINA, El reformismo en España. Madrid, Siglo XXI, 1986.

3 El acta de la reunión fundacional del partido puede consultarse en el Archivo Histórico Nacional, Sección Guerra Civil, en Salamanca (en adelante AHNS), Sección Político-Social, Madrid, carpeta 630 , legajo 873 . 
en un número tan elevado que cabía prever para sus siglas un futuro halagüeño. Decenas de comités locales se constituyeron por todo el país; los altos cargos llovieron sobre los dirigentes del partido, y las elecciones municipales parciales de mayo de 1931 dejaron para sus siglas un buen número de concejales. Así, llegado el momento de dar forma a las candidaturas para las elecciones a Cortes Constituyentes, que habían de celebrarse el 28 de junio de 1931 en su primera vuelta, la DLR pudo presentar ciento quince aspirantes, aunque sólo en cuarenta y cuatro de las sesenta y tres circunscripciones en que a estos efectos se dividía el país ${ }^{4}$.

No habría de responder, empero, la DLR a las expectativas creadas en sus dirigentes a lo largo de los primeros meses de su trayectoria. Los resultados electorales fueron poco satisfactorios. Tan sólo veintidós escaños en una cámara de cuatrocientos setenta asientos, frente a los más de cien de los socialistas y los noventa y cuatro de los radicales de Alejandro Lerroux, exhibían un fracaso sin paliativos que no haría sino confirmarse en los meses siguientes. Podía al principio objetarse que Niceto Alcalá-Zamora continuaba al frente del Gobierno provisional, y que Miguel Maura no había dejado de ser ministro de la Gobernación. Pero se trataba de una situación transitoria, condenada a un final cercano, pues era cada vez más clara en el seno del gabinete la aproximación entre las izquierdas burguesas y los socialistas, interesados ambos en aprobar una Constitución que dotara a la República de un nítido perfil izquierdista. La salida del Gobierno de los dos líderes de la DLR en octubre de 1931, como protesta por la aprobación del anticlerical artículo 26 de la carta magna, no hizo sino dar forma legal a una ruptura que se venía larvando desde hacía mucho tiempo.

¿Qué había pasado? La respuesta no es simple. Dejando de lado la escasa implicación en la campaña electoral de junio de 1931 de los líderes del partido y la inoportuna exhibición pública de sus crecientes diferencias ${ }^{5}$, que pudieron tener cierta importancia, pero nunca decisiva, otros sucesos y factores se nos presentan como mucho más relevantes. Las más de cien iglesias y conventos que ardieron en todo el pais entre los días 11 y 12 de mayo sin duda mostraron a muchos católicos españoles la escasa capacidad que poseían los republicanos conservadores a la hora de refrenar los instintos anticlericales de la izquierda, impresión que hubo de quedar reforzada cuando se aprobó el agresivo artículo 26 de la Constitución. La derecha antirrepublicana concitaría desde ese instante todas las esperanzas de la mayor parte de las potenciales bases sociales de la DLR. Además, la incorporación en gran número a las filas del partido de gentes de incierta lealtad al régimen y, sobre todo, de individuos que, al menos en los medios rurales, se habían distinguido por su apoyo inequívoco a la Dictadura, enturbiaba la imagen de la DLR y alimentaba un proceso de

4 Según un documento hallado en al Archivo Histórico Nacional de Madrid, la «derecha republicana» presentó en las elecciones de junio de 1931 un total de ciento veinticuatro candidatos en sesenta y tres circunscripciones («Ministerio de Gobernación, Sección de Orden Público, Proclamación de candidatos de diputados a Cortes Constituyentes», AHNM, Ministerio del Interior, Serie A, Legajo 31). No obstante, no todos los candidatos recogidos pertenecen al partido. Realmente, DLR debió de presentar unos ciento quince.

5 Para un breve estudio de las relaciones entre ambos lideres, puede consultarse Luis Í́NIGO FERNÁNDEZ, «Niceto Alcalá-Zamora y Miguel Maura. Una relación tempestuosa», en osé Luis CASAS SÁnchez y Francisco Durán Alcalá (coords.), V Jornadas Niceto Alcalá-Zamora y sus contemporáneos, Priego de Córdoba, Patronato Niceto Alcalá-Zamora y Torres-Diputación de Córdoba, 2000, p. 141-164. 
rechazo hacia sus siglas entre los republicanos de izquierda y los socialistas, que se puso enseguida de manifiesto en el proceso de confección de las candidaturas ${ }^{6}$.

Los resultados electorales tuvieron, como era de esperar, efectos demoledores para ambos partidos. El entusiasmo de los militantes se apagaba; la propaganda remitía, y muchos afiliados comenzaban a abandonar la organización, que se estancó enseguida para iniciar luego una rápida contracción. La respuesta que se registró en ambas ramas del republicanismo conservador ante esta situación fue distinta, pero sus efectos fueron semejantes. Los liberales demócratas reaccionaron uniendo su destino político al del lerrouxismo, un socio de mayor peso cuya alianza esperaban les ofreciera mejores oportunidades de acceder al poder y de poner así en práctica siquiera una parte de su programa. Alcalá-Zamora, en cambio, atribuyó el fiasco de la DLR a una imagen conservadora en exceso y optó por dotarla de una apariencia más centrista, que le llevó incluso a cambiar su nombre por el de Partido Republicano Progresista, pero sin contemplar siquiera la posibilidad de sumar sus esfuerzos a los del Partido Radical, a pesar de la creciente similitud entre los postulados de ambas fuerzas. En ambos casos, sin embargo, la derrota electoral y la respuesta de inmediato adoptada ante ella generaron tensiones que acabaron por producir deserciones e incluso, en el caso de los progresistas, una verdadera escisión. Algunas figuras bastante relevantes del ala izquierda del melquiadismo, como Luis de Zulueta o Gustavo Pittaluga, la abandonaron para incorporarse a fuerzas más comprometidas con una interpretación reformista de la República y mayor peso parlamentario. Miguel Maura, en compañía de algunos dirigentes de segunda fila, dejó también el PRP.

Ninguna de estas respuestas solucionó nada. La táctica elegida por el PLD durante el primer bienio de la República obviaba algunos elementos relevantes. El radicalismo era, desde luego, una fuerza emergente y poderosa, cuya vitalidad provenía de la creciente incorporación a sus filas de gentes de sensibilidad conservadora que se habían unido a la República en la esperanza de que ésta garantizara la defensa de sus intereses. Pero el partido dirigido por Alejandro Lerroux se revelaría incapaz de digerir sin problemas tales adhesiones, que, al determinar de un modo cada vez más intenso la política radical, acabaron por producir el descontento, primero, y el abandono del partido, después, de los integrantes de su sector más fiel a su viejo espíritu izquierdista. Roto en dos el PRR tras la escisión liderada por Diego Martínez Barrio, el radicalismo residual quedó, bajo la dirección de Lerroux, del todo desequilibrado en favor de su ala derecha, muy limitado en sus posibilidades de acción política y, sobre todo, infeudado de forma creciente a la CEDA, que arrastró, sin protesta alguna por su parte, al melquiadismo. Éste, embarcado en la alianza con los radicales con la intención de centrar la República mediante la rectificación de los que ambos partidos consideraban excesos del primer bienio, terminó así por convertirse en un mero satélite de la CEDA, sin fuerza alguna para oponerse a sus deseos cada vez más evidentes de acabar con la República o, al menos, transmutarla en un régimen de carácter autoritario y confesional.

Miguel Maura, por el contrario, rectificando su intención inicial de no crear ningún partido nuevo tras su salida del PRP, trató, con la fundación en enero de 1932 del Partido

6 No se trataba tan sólo de eso; los mismos republicanos de izquierda estaban admitiendo también en sus filas a personas de nítida significación monárquica. En el fondo, la izquierda estaba convencida de que la República sólo tenía sentido si servía a sus ideales profundamente reformistas; un régimen moderado en el que todos tuvieran cabida no entraba en sus cálculos. Como síntesis reciente de estos planteamientos puede consultarse Manuel Álvarez Tardio y Roberto VILla GARCía, El precio de la exclusión. La politica durante la Segunda República, Madrid, Encuentro, 2010, en especial p. 17-46. 
Republicano Conservador, de tomar el testigo de la misión histórica para la que había nacido en su momento la DLR y que los progresistas, sin liderazgo ni orientación clara, elevado su fundador a la presidencia de la República, se revelaban ya incapaces de asumir: la incorporación al régimen de las masas conservadoras. Tras unos comienzos ciertamente prometedores, que se concretaron en una intensa campaña de propaganda de alcance nacional, la creación por vez primera en la derecha republicana de una verdadera red de periódicos afines, la simpatía de la prensa moderada, un considerable ritmo de creación de Comités locales y provinciales, y un importante protagonismo en el Parlamento de Miguel Maura, erigido en líder de la política de obstrucción de las oposiciones al Gobierno de Manuel Azaña, el republicanismo maurista reveló su verdadera dimensión al enfrentarse a las urnas en noviembre de 1933. Sus exiguos resultados, inferiores a los obtenidos por la DLR dos años antes, confirmaron la incapacidad de la derecha republicana, democrática, reformista y aconfesional para ganar la batalla del voto conservador a la derecha católica, autoritaria y accidentalista que representaba el partido de Gil Robles. De contradicción en contradicción, también el PRC terminó, a finales de 1935, muy próximo a una CEDA de la que Maura parecía abominar dos años antes.

Sólo los progresistas parecían haber desarrollado una táctica política más consecuente con la orientación centrista que habían asumido en agosto de 1931. Su actitud templada en el transcurso de los debates constitucionales, que habia buscado el consenso en las Cortes como instrumento para limitar el que consideraban excesivo radicalismo de la izquierda, se hizo un poco más agresiva, en línea con la de radicales, liberales demócratas y conservadores, cuando esa izquierda pareció, desde su punto de vista, dispuesta a renunciar a cualquier posibilidad de entendimiento y decidida a permanecer en el poder el tiempo suficiente para la realización de su programa. Del mismo modo, compartiendo con los citados grupos sus deseos rectificadores, se incorporaron durante el segundo bienio a la coalición gobernante dirigida por Lerroux. Sin embargo, su comportamiento en el Gobierno, personificado en la labor reformista moderada que llevó a cabo el progresista Cirilo del Río en el Ministerio de Agricultura, no se apartó de su compromiso republicano ni se dejó tentar, como algunos radicales, por el derechismo de la CEDA. En coherencia con esta actitud, cuando el partido católico exigió y logró su incorporación al Gobierno, el PRP lo abandonó, desconfiando de su lealtad republicana.

No obstante, la total identificación de la táctica seguida por el PRP con las pautas trazadas desde la Presidencia de la República no puede por menos que mover a la sospecha de que el partido no hacía otra cosa que seguirlas al pie de la letra. Actúa a favor de esta impresión, además del testimonio de actores clave en la política del momento, como Gil Robles o Lerroux, la escasa dimensión a la que el progresismo había quedado reducido entonces, que hace inexplicable su presencia continuada en el Gobierno, aun apelando a la utilidad marginal de sus escaños, si no se atribuye aquella a la imposición más o menos explícita de Alcalá-Zamora. El presidente, convencido de que la situación del país así lo exigía, podía de ese modo controlar mejor la acción de los gobiernos e incluso derribarlos cuando le pareciera oportuno. En este caso, la política del PRP no sería otra cosa que la política de un solo hombre, por lo que no debe extrañar el sacrificio que se le impuso en beneficio del experimento neocaciquil que vino a encarnar el Partido del Centro de Manuel Pórtela Valladares, nacido antes de la mente del Jefe del Estado que de la del Jefe del Gobierno, por más que éste fuera el llamado a ponerla en práctica. Alcalá-Zamora creyó posible erigir de la nada una fuerza política de nuevo cuño sin otro cimiento que la capacidad del Ministerio de Gobernación y de los gobiernos civiles de él dependientes para condicionar el sufragio 
de los ciudadanos y la confección de listas electorales, como si el país, recién nacido a la era de la política de masas, permaneciera aún en manos de los viejos caciques de la Restauración.

El fracaso de tal experimento de ingeniería política estaba cantado, pero a su sombra pudo el PRP alcanzar, en los comicios de febrero de 1936, resultados significativamente mejores que los de poco más de dos años antes. No revelan, sin embargo, estas cifras un mayor apoyo de la opinión a sus candidaturas, sino los réditos de una presión ejercida desde el Gobierno que forzó la incorporación de candidatos progresistas en algunas listas de la derecha. Y respecto a los escaños cosechados por sus partidos afines, melquiadistas y conservadores, no son mucho mejores. Ni unos ni otros constituyen ya, a estas alturas, sino restos humeantes de lo que otrora pareció capaz de encarnar las esperanzas de la opinión conservadora.

\section{Las razones de un fracaso}

¿Cuáles fueron las causas de este fracaso sin paliativos del republicanismo templado? ¿Hay que buscarlas, acaso, en los manifiestos errores tácticos de sus líderes? ¿Quizá eran, por el contrario, su ideología y su programa los que no acababan de conectar con la opinión conservadora del pais? ¿Se trataba de problemas de organización? ¿O debemos recurrir, sin más, al contexto histórico, poco favorable a las opciones sosegadas, en que se vieron obligados a operar?

Empecemos por las ideas. No cabe duda de que estos partidos poseían señas de identidad ideológicas bien definidas. Todos ellos compartían una cosmovisión similar y, por consiguiente, realizaban un diagnóstico afín sobre los problemas más graves que afrontaba la sociedad y las recetas más eficaces para resolverlos. Verdaderos clásicos del liberalismo, creían con firmeza en la intangibilidad de los derechos del individuo, la propiedad sobre todos ellos; rechazaban cualquier argumento que permitiera eludirlos, aun en aras de una supuesta mejora del bienestar colectivo, y desconfiaban de las políticas económicas orientadas a toreer las reglas del mercado. «Mientras el trabajo no tenga una base ética proclama Melquíades Álvarez en enero de 1932-serán el interés y el egoísmo los creadores de riqueza) ${ }^{7}$. Idea muy semejante a la que recogen en su ideario los progresistas, para quienes

España no resistirá la experiencia de improvisar ahora un sistema económico de tipo socializante. Hay que ahuyentar este peligro y hacer que los factores económicos entren sin temor en el juego de la producción, mediante el rápido establecimiento de un orden enérgico y serio de garantías. E1 PRP ha de colaborar al robustecimiento de la economía individualista y liberal, única que en este momento histórico de España puede conjurar la crisis e intensificar el torrente circulatorio de la riqueza ${ }^{8}$.

Republicanos convencidos, lo eran de una República «viable, gubernamental y conservadora», como insistió en definirla el que sería más tarde su primer presidente, Niceto Alcalá-Zamora, en su célebre discurso del teatro Apolo de Valencia, el 13 de abril de 1930, en el que proclamó de manera oficial su ruptura con la Monarquía9. Una República, por ende, sin servidumbres ideológicas, un régimen imparcial, abierto a

7 Discurso de Melquíades Álvarez en el Teatro de la Comedia de Madrid, 3 de enero de 1932, Ahora. 5 de enero de 1932.

8 Indice Ideario del Partido Republicano Progresista, VII, Economía. AHNS, Político-Social, Madrid, carpeta 1897.

9 Niceto Alcala-Zamora, Discursos, Madrid, Tecnos, 1979, p. 494. 
gobiernos de izquierdas y derechas, capaz de integrar en su seno a todos los ciudadanos y verdaderamente democrático, esto es, respetuoso de la ley, sagrada en tanto emanada de la voluntad general. «Abiertos en la República los cauces de la legalidad, sólo legalmente y en su tiempo debe manifestarse el pueblo. No hay régimen que pueda vivir en el descontento y en la desobediencia constante. Constituido el gobierno, hay que respetarlo», escribe el melquiadista Mariano Cuber en $1931^{10}$.

Neutros en materia religiosa, valoraban en la fe cuanto en ella había de útil para preservar el orden social, pero comprendían a un tiempo la necesidad de romper el vínculo perverso que unía al Estado con la Iglesia y someter a ésta a algún tipo de control que limitara sus históricos privilegios.

En lo espiritual -proclama Alcalá-Zamora- la República no puede ser la continuación del privilegio teocrático ni la mediatización de la soberanía del poder civil, pero no tiene derecho a ser la persecución del sentimiento religioso, que la deshonraría, sino el respeto a todas las creencias, que la enaltece ${ }^{11}$.

Liberalismo, republicanismo y laicismo marean, pues, las tres grandes señas de identidad de los partidos que nos ocupan. Pero la ideología ofrece por sí sola escasas explicaciones, a no ser que se la entienda como inspiración, no exclusiva, de un programa político. Sin embargo, hecho esto en el caso de la derecha republicana, tampoco son muy significativas las diferencias entre melquiadistas, progresistas y conservadores, aunque los amigos de Alcalá-Zamora tienden a aparecer en la mayoría de los asuntos como más moderados mientras los de Maura se muestran más radicales en su conservadurismo, todo ello dentro de una línea programática por lo demás bastante homogénea que, algo timorata, tendía con excesiva frecuencia a dejar en manos del tiempo la solución de los problemas.

Así, armonicistas en lo social, apenas lograban esconder su interés prioritario por la preservación del capitalismo. El objetivo último de toda política económica, sostenían, había de ser el incremento global de la riqueza, pues sin riqueza que repartir no podía resolverse el problema de la pobreza. Este incremento de la riqueza no podía alcanzarse, no obstante, en una situación de enfrentamiento entre el capital y trabajo, sino sólo a través de la colaboración entre ambos. Destruir el primero con la intención de obtener supuestos beneficios para el segundo no podía ser más que contraproducente. Como señalaba el que podría pasar por ideólogo fundamental del melquiadismo, Mariano Cuber, «Capital y trabajo son elementos que se completan y que sin su armonía no hay progreso ni bienestar posible en el mundo» ${ }^{12}$. Ideas, por otra parte, genéricas que, forzadas a descender al terreno de lo práctico, se quedaban en lo puramente arbitral, en la mera intermediación estatal entre obreros y patronos. Así, el programa del Partido Republicano Conservador defendía la existencia de los jurados mixtos, pero otorgándoles una fisonomía bien distinta de la que poseían, pues, temiendo su instrumentalización por parte de los sindicatos, propugnaban su conversión en auténticos tribunales presididos por magistrados de lo social designados por oposición y sometidos al juicio último de un organismo central con capacidad para revocar sus acuerdos ${ }^{13}$.

10 Mariano CuBER, «Sobre el acto del Palace. Melquíades Álvarez. Criterio (III)», El Noroeste, 7 de junio de 1931.

11 Discurso pronunciado en la plaza de toros de Jaén el 21 de junio de 1931, en Niceto AlCALÁ-Zamora, Discursos, p. 543.

12 M. CUBER, Antisocialismo. Madrid, Reus, 1935, p. 93.

13 Programa del Partido Republicano Conservador, epígrafe «Política Social», Archivo de la Real Academia de la Historia (en adelante ARAH), 11/8987. 
De igual modo, autonomistas en lo territorial, no llevaban sus tímidos designios de descentralización mucho más allá, y ello en el mejor de los casos, de un escaso autogobierno regional pronto a batirse en retirada ante el más mínimo atisbo de riesgo, real o percibido, de desintegración política de España. En modo alguno se trataba, de un nuevo modelo de Estado, alternativo al centralista heredado del liberalismo decimonónico, como precisa sin ambages Alcalá-Zamora en un discurso sobre el tema pronunciado en las Cortes el 23 de septiembre de 1931:

...nada de traje a patrón con el que hayan de vestirse todas las regiones; una gradación diferencial, flexible y sutil en los matices dentro de la cual puedan vivir las regiones que no sientan el impulso de la autonomía y aquellas que lo sientan con plena intensidad y que se crean capacitadas por la plena madurez política... ${ }^{14}$.

Estamos, pues, ante una simple receta, muy forzada, para atemperar los ánimos de los nacionalistas catalanes y vascos. Melquíades Álvarez lo dejó bien claro en un discurso pronunciado en Mora de Toledo en mayo de 1932:

...la autonomía -dijo el vehemente tribuno asturiano- no es la segregación. No consiste en arrebatar las facultades inherentes a la soberanía del Estado para transmitirlas a personalidades históricas efímeras. Estas facultades son inalienables. No pueden cederse ${ }^{15}$.

Por lo cual no debe extrañarnos que a la hora de plasmar en medidas concretas ese proclamado autonomismo, apenas si podía aplicarse con propiedad el apelativo autonomía al régimen de autogobierno que los republicanos conservadores se mostraban dispuestos a conceder a las regiones. Ni siquiera se contemplaba la existencia de parlamentos regionales o competencias transferidas. En lo que se pensaba, más bien, es en aquel viejo principio de la autorquia que Gumersindo de Azcárate definiera mucho tiempo antes como la facultad de cada región «... para regirse y gobernarse a sí misma dentro de la ley», una autonomía, en fin, meramente administrativa y privada de cualquier capacidad política real.

Cautelosos por igual se mostraban los republicanos conservadores respecto a la cuestión agraria. Siempre temerosos de los males que pudieran derivarse de un Estado terrateniente, aceptaban la expropiación indemnizada de las grandes fincas, pero tan sólo como destino temporal de unos predios que habían de convertirse a la mayor brevedad posible en propiedad plena de las familias campesinas, pues, como burgueses que eran en última instancia, deseaban que la reforma agraria diese origen a una sólida clase media rural de instintos conservadores que actuara como firme sostén del régimen y del orden social. Así lo señalaba con toda claridad el ideario del PRP, que defendía «... la creación de la pequeña propiedad rural, omitiendo los asentamientos temporales o de otro tipo análogo» ${ }^{16}$, aunque no por ello, incurriendo así en una cierta contradicción, dejaba de preocuparse por el riesgo de una excesiva atomización de la propiedad rural que no haría sino dificultar la tecnificación del campo y por ende, el desarrollo de la agricultura ${ }^{17}$. El proyecto de reforma agraria presentado en las Cortes por Niceto Alcalá-Zamora el 25 de agosto de $1931^{18}$, así como el proyecto de Ley de Arrendamientos Rústicos registrado en la Cámara el 23 de

14 Niceto Alcalá-Zamora, Discursos, p. 319.

15 El Noroeste, 4 de mayo de 1932.

16 AHNS, Político-Social, Madrid, carpeta 1987.

17 De hecho, su denominado Programa Minimo afirma la necesidad de limitar la exagerada concentración de la propiedad, pero «....con índices suficientemente altos para fomentar el gran cultivo y la explotación ganadera) (AHNS, Político-Social, Madrid, Carpeta 630, Legajo 873).

18 Diario de Sesiones de las Cortes Constituyentes, $\mathrm{n}^{\circ} 26,25$ de agosto de 1931, Apéndice $\mathrm{n}^{\circ} 9$. 
febrero de 1934 por el ministro progresista de Agricultura Cirilo del Río ${ }^{19}$, ofrecían los ejemplos más completos y acabados del programa agrario del republicanismo conservador.

Por último, conscientes de la importancia de la cuestión religiosa en el imaginario colectivo de los españoles, pero sin apartase de sus planteamientos ideológicos sobre la cuestión, analizados más arriba, no dieron a ésta otra respuesta que la conveniencia de un Concordato capaz a un tiempo de privar a la izquierda de un arma de gran potencial movilizador y situar a la Iglesia en el marco jurídico que le correspondía en un régimen democrático y neutro en materia de fe. La separación entre la Iglesia y el Estado, pues, era conveniente, pero no sin ciertas medidas de control de la primera por el segundo, y, por supuesto, sin que los derechos de aquella, iguales en todo a los del resto de ciudadanos, resultaran lesionados en lo más mínimo. Ni expulsión de las órdenes religiosas, ni limitación de sus actividades económicas ni, menos aún, cierre de sus colegios tenían cabida en los programas de los partidos republicanos conservadores.

Con todo ello, fuerza es decirlo, el republicanismo templado tendía a situarse frente a la mayoría de los problemas más cerca de una derecha a la que le aproximaba la sensibilidad, el talante y el instinto de clase, pero de la que le alejaba su sincero compromiso con un régimen republicano, parlamentario y no confesional, que de una izquierda cson la que comparte ese compromiso, pero de la que le alejaba mucho más la que consideraba su vergonzosa claudicación ante un socialismo que, desde su punto de vista, la había conducido a pervertir su republicanismo. Merecen, pues, el apellido de derecha republicana estos partidos tan poco semejantes en muchas cosas a aquellos que en estos años contemplaban como algo natural la identificación entre la República y las izquierdas. Eran, sin duda, conservadores, aunque de esa manera inteligente que le hacía decir al editorialista del rotativo melquiadista gijonés El Noroeste en octubre de 1931:

...no hay otra salida ni otro remedio a la realidad que vivimos que andar hacia adelante constantemente, despacio si se quiere y es posible; pero andar siempre, so pena de exponemos, si no lo hacemos, a que un día las fuerzas ocultas que mueven el mundo nos hagan dar uno de esos saltos tremendos que registra la Historia como cataclismos ${ }^{20}$.

Pero ese conservadurismo suyo no era tampoco el de las derechas españolas, como su republicanismo no era el de las izquierdas. Y por ello, aislados por ambos lados, no podían influir en gran medida en la política del régimen, que les condenaba a la marginalidad. Programas e ideología, por tanto, actuaron, en cierta medida, como factores negativos en la lucha de estos partidos por acceder al poder. La España de los años treinta no parecía un buen lugar para las medias tintas.

Sin embargo, ni la ideología ni el programa fueron con mucho los factores más determinantes del fracaso del republicanismo conservador. En realidad, ni una ni otro se mostraban demasiado alejados de la sensibilidad de muchos de los más recientes afiliados y votantes del exitoso Partido Radical, por ejemplo. Un peso mucho mayor corresponde a la organización.

La estructura general de la Derecha Liberal Republicana quedó ya definida en una carta que remitía en fecha tan temprana como el 26 de agosto de 1930 su Secretaría Central al secretario de un Comité local que, como tantos otros por entonces, se había dirigido a ella para informarle de su constitución y solicitarle instrucciones ${ }^{21}$. Aunque en aquellos instantes,

19 Diario de Sesiones de las Cortes, $\mathrm{n}^{\circ}$ 41, 23 de febrero de 1934, Apéndice $4^{\circ}$.

20 Editorial sin título, El Noroeste, 18 de octubre de 1931.

21 AHNS, Político-Social, Madrid, carpeta 625, legajo 869. 
previos a la celebración de la primera Asamblea Nacional del partido, no podemos sino considerar la información como orientativa, sabemos que, al menos en sus grandes líneas, resultó válida. La carta diseñaba un entramado organizativo similar a lo que había sido la práctica habitual de los partidos republicanos, aunque matizada por la intención de adaptarla a los nuevos tiempos, que imponían una creciente participación política de las masas, y, por ende, hacían conveniente introducir mecanismos de representación y movilización de los simpatizantes y afiliados. La célula básica era el Comité municipal, que en las localidades en las que el volumen de afiliados así lo aconsejara, podía articularse en Comités de distrito. Por encima de aquéllos, los Comités provinciales y regionales coordinarían la labor de sus homónimos locales y servirían de intermediarios, aunque no en todas las actividades, entre estos y la organización central del partido, encarnada en un órgano permanente de carácter burocrático, la Secretaría Central, afecto a otro de índole política, el Comité Nacional, que lo gobernaría siguiendo las pautas marcadas por las Asambleas Nacionales anuales.

Nos encontramos, pues, en apariencia, ante un partido que intenta incorporarse a los usos y costumbres políticos de la democracia de masas. De la lectura de sus reglamentos se deduce que su organización ejercía un control considerable sobre sus afiliados. Tamizaba su admisión, imponiéndoles incluso en ocasiones el requisito de ser presentados por militantes de probada lealtad; se aseguraba de arrancar de ellos el acatamiento a las ideas y la disciplina del partido; registraba con detalle sus derechos y obligaciones, cargándoles con el pago de cuotas regulares, y no se olvidaba de entregarles un carnet para fortalecer su sentido de pertenencia a la comunidad de sentimientos y fines que el partido pretendía constituir.

No debemos, sin embargo, llamarnos a engaño. La realidad del progresismo no era ni tan moderna ni tan democrática como aparentaba. La representatividad de sus órganos de gobierno era ficticia. En las asambleas, decenas de Comités de la misma región o provincia elegían a una misma persona, que, elocuentemente, solía ser el prohombre del partido en la circunscripción. ${ }^{22}$ El programa de gobierno nada tenía que ver con la opinión de los afiliados. Su aprobación en la Primera Asamblea Nacional del partido se produjo mediante aclamación unánime de un borrador redactado por Alcalá-Zamora tras una conversación con sus diputados afines. ${ }^{23} \mathrm{La}$ financiación, desde luego, provenía de fuentes bien distintas de las cuotas de los afiliados, exiguas en la cantidad y erráticas en la regularidad con que afluían a las arcas del partido. La autonomía de las secciones que acompañaban su nombre con tal calificativo -Juventudes, Sección Femenina- no iba más allá de actividades tan políticamente inocuas como los concursos de parchís o la recogida de juguetes para los niños pobres, que poco podían interesar a los Comités locales y provinciales. La implantación social y geográfica del partido, por último, no pasaba de algunas regiones muy limitadas y concretas que, no siendo de las más avanzadas económica y socialmente, parecen demasiado susceptibles de soportar aún un clientelismo político cuya probabilidad pesa como una losa sobre su supuesta modernidad. Y aunque los conocemos con menos detalle, todo lo dicho hasta aquí podría servir para describir la organización interna de melquiadistas y mauristas.

22 Las actas de los Comités locales confirman que esta práctica debía de ser bastante habitual. Así, en Ávila, diez de los doce Comités representados en la Cuarta Asamblea Nacional habían elegido como representante a San Román; todos los gaditanos habían escogido a Manuel Rodrigo, y veintiuna de las veintidós agrupaciones jienenses se habían pronunciado por Miguel Pastor (AHNS, Político-Social, Madrid, carpeta 1897).

23 Así lo relató Sánchez-Covisa, uno de los vicepresidentes de la mesa de La Asamblea (El Sol, 4 de agosto de 1931). 
Parece, pues, que la deficiente y anacrónica organización de los partidos republicanos conservadores pudo desempeñar un papel de cierta relevancia en lo limitado de sus logros. Sin embargo, antes de concluir parece oportuno preguntarse qué peso correspondió en ello a los factores externos, $o$, en otras palabras, de qué modo afectó el contexto histórico en el que se vieron forzados a actuar al pobre resultado que cosecharon.

No cabe duda de que las características del entorno socioeconómico en el que se veían forzados a operar estos republicanos templados no era demasiado favorable. Por una parte, su mensaje ofrecía por vez primera a las bases sociales de la derecha española una nueva forma de ser conservador que separaba de forma clara la religión y la política, a la vez que supeditaba de manera inseparable a ésta a las formas del parlamentarismo democrático. Se trataba, pues, de una derecha distinta a la que los españoles conocían, ya que hasta ese instante sólo había existido en España una forma de ser conservador: abrazando, a la vez, el catolicismo y la Monarquía.

Por otra parte, las tensiones sociales crecientes en las que se vio forzado a existir el nuevo régimen, algunas de ellas provocadas por su mera existencia y las expectativas frustradas que despertó, no constituían un buen caldo de cultivo para el desarrollo de opciones templadas como la que encarnaba el republicanismo conservador. Es posible que sus llamadas a la moderación y al reformismo evolucionista como mejor estrategia para la defensa de los intereses de las clases sociales acomodadas hubieran funcionado en una coyuntura distinta, de mayor crecimiento económico y reivindicaciones obreras menos exigentes. Pero en el marco de una profunda depresión mundial que cerraba las válvulas de escape de la lucha de clases y tendía a fomentar los radicalismos en ambos extremos del espectro político, el mensaje de gentes como Miguel Maura o, sobre todo, Niceto AlcaláZamora parecía abocado a convertirse en la voz que clama en el desierto.

\section{Conclusiones}

En síntesis, el trágico destino del republicanismo conservador se debió a la conjunción de dos tipos de factores. El primero es de índole interna y se relaciona con la carencia en los partidos de esta corriente de los instrumentos necesarios para competir con probabilidades de éxito en la nueva era de la política de masas: mecanismos de financiación adecuados, medios eficaces de difusión del ideario y cauces de participación de los afiliados en la dirección del partido. Todo ello convierte al PLD y la DLR, primero, y al PRP y el PRC, después, en meros apéndices de las decisiones de sus líderes, cuyo criterio personal, a menudo enturbiado por sus prejuicios, sus intereses, sus simpatías y antipatías e incluso sus estados de ánimo, acaba por erigirse en determinante a la hora de decidir la orientación política de cada partido, lo que explica su falta de coherencia generalizada o el hecho de que ni siquiera llegue a plantearse en serio una fusión que en la izquierda, por el contrario, sí tiene lugar.

El segundo tipo de factores es de índole externa y se refiere al contexto histórico en el que se veía obligado a operar el republicanismo conservador. Por una parte, su mensaje, que ofrecía a la derecha española la alternativa de una nueva forma de ser conservador que separaba por vez primera la religión y la política y vinculaba de manera inseparable a ésta con las formas del parlamentarismo democrático, era quizá en exceso avanzado para el nivel de desarrollo cultural de la sociedad española. Por otra parte, es posible que su tímido reformismo evolucionista hubiera captado la atención de las clases medias conservadoras en una coyuntura de menores tensiones sociales. Pero la derecha social percibía en las 
masas izquierdistas y en sus líderes una creciente radicalización que incrementaba su pánico a la revolución y tendía a arrojarla en brazos de las opciones más extremas.

Para terminar, resta preguntarse qué papel desempeñó el fracaso de la derecha republicana, si es que desempeñó alguno, en el destino final del régimen. La respuesta, por supuesto, no es simple. Cabe señalar, no obstante, que cualquier régimen democrático requiere para subsistir de la existencia de al menos dos fuerzas políticas capaces de turnarse pacíficamente en el ejercicio del poder. Y la Segunda República no contó con ninguna de esas fuerzas. A la izquierda, el PSOE sólo era republicano por conveniencia, y su respeto por las formas del parlamentarismo liberal se limitaba a la utilidad que pudiera extraer de ellas, de modo que la adhesión al régimen de buena parte de sus masas y algunos de los más conspicuos entre sus líderes comenzó a flaquear desde el instante mismo en que consideraron que no servía a sus intereses. Y en cuanto a la derecha, la CEDA tenía de la República una percepción no muy distinta, puramente instrumental, pues sólo veía en ella un paso previo a la implantación de un régimen autoritario, corporativo y confesional del todo incompatible con la democracia parlamentaria. Cabe pensar que la tarea de sustentar el régimen recaía, por tanto, sobre las espaldas de los partidos republicanos burgueses. La izquierda, que parecía entenderlo así, se embarcó de hecho en un proyecto que la condujo a un notable grado de integración, encarnado en la constitución de la denominada Izquierda Republicana. La derecha, por el contrario, no lo hizo, y sin una derecha republicana fuerte, capaz incluso de concertar con la izquierda burguesa un gran pacto de Estado que asegurase, llegado el momento, la supervivencia del régimen frente a los crecientes ataques de la izquierda marxista y la derecha autoritaria, la República estaba casi condenada. 